\title{
СОВЕРШЕНСТВОВАНИЕ НАЛОГООБЛОЖЕНИЯ ДОХОДОВ ФИЗИЧЕСКИХ ЛИЦ КАК ФАКТОР УМЕНЫШЕНИЯ УРОВНЯ МОНЕТАРНОГО НЕРАВЕНСТВА
}

\author{
Е.С. Вылкова
}

Проанализированы методики измерения уровня монетарного неравенства доходов, проблемы достоверности производимых расчетов соответствующих показателей, их специфики в страновом и поселенческом разрезах. Приведены результаты статистических расчетов по уровню неравенства доходов исходя из данных Всемирного банка, Росстата и других организаций. Рассмотрены конфигурация и варианты стратификации неравенства по доходам в различных странах и России. Сделан вывод, что уровень неравенства в стране по доходам массовых слоев населения следует признать более высоким, чем в европейских государствах, и низким по сравнению со странами БРИКС, при всей дискуссионности и вариативности получаемых результатов его измерения. Произведен анализ системы подоходного налогообложения граждан в государствах ОЭСР. Внесены предложения по реформированию порядка исчисления НДФЛ в России.

Ключевые слова: монетарное неравенство, доходы физических лиц, налог, прогрессивное налогообложение, прожиточный минимум.

JEL-классификация: D63, H21, H24.

DOI: $10.46782 / 1818-4510-2021-2-46-54$

Материал поступил 12.04.2021 2.

В настоящее время зарубежные и российские исследователи всесторонне изучают подоходное налогообложение и неравенство. Оно является объектом пристального внимания зарубежных ученых. Согласно данным базы Scopus, словосочетание «ставка налога» содержится в заглавиях, аннотациях и ключевых словах более тысячи публикаций. В 17 работах рассматриваются непосредственно особенности прогрессивной шкалы налогообложения. К наиболее цитируемым относится (Paes, Bugarin, 2006). Интересно, что в этой работе содержится утверждение: плоская шкала налогов усиливает неравенство и снижает эффективность бразильской налоговой системы. Следует назвать также публикацию (Kim, 2018), где анализируется ряд моделей прогрессивного налогообложения. R.J. Cebula (2019), имеющий много публикаций по подоходному индивидуальному налогу (РІT), акцентирует внимание на его ставках при налогообложении ценных бумаг.
Российские ученые и практики также написали много трудов по различным вопросам подоходного налогообложения. Л.Р. Слепнева и Д.А. Павлуцкая анализируют проблемы администрирования НДФЛ и специфику налогообложения самозанятых ${ }^{1}$. Е.Н. Орлова, С.С. Быков (2012) и Н.В. Покровская (2017) оценивают значимость НДФЛ в формировании доходной части местных бюджетов. Н.Г. Викторова и Л.К. Аитова (2016) исследуют индивидуаль-

${ }^{1}$ Слепнева Л.Р., Павлуцкая Д.А. 2015. Проблемы администрирования налога на доходы физических лиц и взносов во внебюджетные фонды. Байкальские экономические чтения. Социально-экономическое развитие регионов: проблемы, перспективы: материалы международной научно-практической конференции. Улан-Удэ: Восточно-Сибирский государственный университет технологий и управления. С. 117-121; Слепнева Л.Р. 2020. Налогообложение самозанятых: проблемы и решения. Социально-экономическое развитие России и Монголии: проблемы и перспективы: материалы VII Международной научно-практической конференции. Улан-Удэ: Восточно-Сибирский государственный университет технологий и управления. С. 232-236.

* Вылкова Елена Сергеевна (vylkova-es@ranepa.ru), доктор экономических наук, профессор, Северо-Западный институт управления Российской академии народного хозяйства и государственной службы (г. Санкт-Петербург, Россия). 
ное подоходное налогообложение в странах БРИКС. Е.Ф. Киреева (2012) уделяет внимание подоходному налогообложению при исследовании налоговой политики стран - членов Европейского союза и членов Таможенного союза. Е.А. Лаврентьева (2016) раскрывает специфику налогообложения доходов работников водного транспорта. М.Н. Конягина (2019) отмечает значимость цифровизации в сфере подоходного налогообложения.

Автор данной статьи в своих работах неоднократно обращался к проблематике подоходного налогообложения физических лиц, рассматривая концептуальные основы его реформирования с опорой на анализ опыта в этом вопросе более чем 100 стран (Вылкова, Тарасевич, 2010), вопросы совершенствования налогообложения труда в России и государствах, входящих в ОЭСР (Вылкова, Тарасевич, 2018), научно обоснованного формирования налоговых льгот (Вылкова, Красавин, 2011), взаимосвязи подоходного налогообложения и инициативного бюджетирования (Вылкова, Шматко, 2020).

Следует отметить, что проблематике неравенства не столь уж часто уделяется внимание авторов, пишущих про подоходное налогообложение. В большинстве соответствующих публикаций о нем упоминается как о существующей проблеме, требующей решения, или приводятся общие рассуждения, фрагментарные расчеты показателей его уровня. Как правило, это индекс Джини, без учета как имеющихся наработок по теории неравенства, так и различных других альтернативных показателей и метрик, позволяющих оценивать неравенство.

Наибольшее внимание зарубежных исследователей привлекает проблематика монетарного (по доходу или по богатству) неравенства ${ }^{2}$ (Atkinson, 2015; Milanovic, 2016; Piketty, 2014; Stiglitz, 2012), хотя есть интересные публикации и по немонетарному неравенству (Grusky, 2011).

Различным аспектам неравенства в России посвящены работы отечественных экономистов и социологов. Прежде всего

${ }^{2}$ World Inequality Report 2018. World Inequlaity Lab. URL: https://www.semanticscholar.org/paper/Worldinequalityreport-2018-Alvaredo-Chancel/dece3e5a9185900fdea7a82b0 c42ae90f40a5932 следует назвать Р.И. Капелюшникова (2017, 2019, 2020), его исследования проблем неравенства ежегодно публикуются на страницах журнала «Вопросы экономики». Вопросы неравенства изучает С.В. Мареева (2016, 2018, 2020). Факторы неравенства доходов россиян исследуют Л.Н. Овчарова, Д.О. Попова, А.М. Рудберг (2016), Е.М. Авраамова и Т.М. Малеева (2014), Л.М. Григорьев и В.А. Павлюшина (2017), А.А. Салмина (2019) и др. Автор данной статьи рассматривал неравенство при анализе возможностей оценки уровня справедливости налогового законодательства (Вылкова, 2017) и использования справедливодейственного подхода при реформировании налогообложения доходов и имущества физических лиц (Вылкова, Тарасевич, 2017).

Следует отметить, что авторы, занимающиеся вопросами неравенства, как правило, лишь указывают на необходимость реформирования налогообложения как фактора уменьшения уровня монетарного неравенства доходов и не предлагают ничего конкретного.

Крайне востребованным в современных условиях является восполнение научного разрыва между исследованиями подоходного налогообложения и неравенства, что является целью данной статьи. Для ее достижения последовательно решаются следующие задачи:

на базе детального изучения методологии и результатов различных вариантов расчетов уровня монетарного неравенства по доходам формируются направления реформирования НДФЛ в России;

на основе анализа действующего порядка исчисления индивидуальных подоходных налогов (РІТ) в странах ОЭСФ сформулированные предложения наполняются конкретным содержанием относительно уровня ставок и количества шедул прогрессии, а также размера необлагаемого дохода.

Логика изложения материала в статье продиктована перечисленными задачами.

\section{Измерение уровня монетарного неравенства доходов}

Проблемы неравенства и специфику его измерения изучают различные международные организации: ООН, МВФ, Мировой Банк и др. Их исследуют ученые, 
социологи, экономисты, политологи. Ученые анализируют природу неравенства, ищут варианты максимально точного измерения его уровня.

Рост неравенства - восходящий тренд в последнее десятилетие в мире в целом и в конкретных странах. В России уровень неравенства, по данным многих исследований, один из самых высоких в мире.

Принципиальной проблемой является измерение неравенства. Во-первых, любой индикатор в экономических науках имеет множество вариаций. Кроме общеизвестного индекса Джини, используются также индексы Тейла, Гувера, Адкинсона, показатели поляризации, показывающие соотношение самых низкодоходных групп с супердоходными. Во-вторых, сложность в области измерения неравенства заключается в трудности доступа к группам самых богатых и получения по ним достоверных сведений. Сверхбогатые («шпиль») практически недоступны интервьюерам и возможно использовать только экспертные оценки. Даже самые богатые, которые, как правило, попадают в опрос, это в общем-то средний класс.

Статистика в различных организациях, публикующих статистические данные по неравенству доходов, различается.

Всемирный банк ${ }^{3}$ берет чистые данные. Из 60 доступных стран у России 37 позиция по индексу Джини. По данным Bceмирного банка, она имеет среднее значение неравенства, более высокое, чем в европейских странах, но меньше максимальных значений в мире. Среди стран БРИКС индекс Джини в России, по данным Всемирного Банка, является наиболее низким. Получающееся, по данным этой организации, сокращение неравенства в стране в последние годы вряд ли есть в реальности, так как очевиден резкий рост числа миллиардеров за последнее время. Крайняя бедность (на уровне борьбы за выживание), по критериям Всемирного банка, для России совершенно не характерна. По еще одному индикатору, концентрации доходов, у нас наблюдается приблизительно среднее значение по результатам обследования разных слоев населения.

\footnotetext{
${ }^{3}$ URL: https://data.worldbank.org
}

Данные ФСГС (Росстат) существенно менее чувствительны к рецессиям, кризисам, чем данные Всемирного Банка, так как Росстат делает некоторые дооценки с учетом нормального распределения и теневого сектора экономики. В результате, по данным Росстата, происходит сглаживание скачков изменений индекса Джини, и его значение получается более высоким по сравнению с данными Всемирного банка ${ }^{4}$.

Согласно Люксембургскому исследованию доходов 5 , значение индекса Джини (с использованием шкал эквивалентности для учета экономии на масштабе потребления) в России близко к западным странам в части исследования массовых слоев населения. Конфигурация неравенства, по данным этого исследования, достаточно похожа на Европу и сильно отличается от Бразилии, Венесуэлы, Китая, других стран БРИКС, Латинской Америки.

Кроме названных организаций, есть и другие, которые предпринимают попытки измерения уровня неравенства: World Inequality Database ${ }^{6}$, Credit Suisse ${ }^{7}$ Европейский банк реконструкции и развития ${ }^{8}$.

Изучив общие вопросы определения уровня неравенства доходов, становится очевидно, что никакие показатели нельзя принимать за истину в последней инстанции.

Рассмотрим конфигурацию неравенства по доходам. Наибольший интерес для целей данного исследования представляют слои населения наиболее низкодоходные («хвост») и супер высокодоходные («шпиль»).

По данным ФСГС России ${ }^{9}$, доля населения с денежными доходами ниже величины прожиточного минимума с 1992 г. имела тенденцию к снижению с уровня в 33,5\% (49,3 млн чел.) до минимума в 2012 г. - 12,5\%. В 2019 г. доля бедных составляла 12,3\% (18,1 млн чел.). К среднему классу, по данным Всемирного банка, в России возможно относить людей с дневными доходами на уровне бо-

\footnotetext{
4 URL: https://www.gks.ru/storage/mediabank/ urov_32g.doc

5 URL: http://www.lisdatacenter.org

${ }^{6}$ URL: https://wid.world

7 URL: www.credit-suisse.com

8 URL: https://www.ebrd.com/ru/home.html

9 URL: https://www.gks.ru/storage/mediabank/urov $51 \mathrm{~g}(1) \cdot \mathrm{doc}$
} 
лее 10 долл. США в день, что составляет порядка $70 \%$ населения.

Интересно посмотреть на возрастание доходов $1 \%$ богатейшего населения в исторической ретроспективе. По числу лиц, входящих в список ФОРБС ${ }^{10}$, Россия оказывается в числе лидеров, обгоняя практически все страны: $1 \%$ богатейших россиян обладает более чем $50 \%$ богатства страны.

Динамика отрыва в России «шпиля» от остального населения нарастает, что дает основания говорить о необходимости регулирования этого процесса налоговыми способами и методами, в том числе путем введения прогрессивной шкалы НДФЛ. Прогрессивность налогообложения доходов физических лиц наряду с введением определенного минимума доходов, не облагаемых НДФЛ, призваны помочь в решении основных проблем в сглаживании неравенства: подтягивании низов к середине, обеспечении устойчивости середины, снижении «шпиля».

Принятию грамотного и экономически обоснованного решения в этом вопросе могут помочь исследования, посвященные доходной стратификации слоев населения (Тихонова, 2018; Мареева, Слободенюк, 2018; Мареева 2020). Выделяются 5 слоев населения на основе медианного дохода, который, по данным Росстата, в месяц составлял в 2019 г. 26365 руб. От этого значения $50 \%$ идентифицируется как граница бедности; $75 \%$ - граница уязвимости к бедности; 75-125\% - медианная группа; 125$200 \%$ - среднедоходная группа; выше $200 \%$ - высокодоходная группа среди массовых слоев населения. Как видим, в российском обществе превалируют массовые средние группы.

Примечательно, что авторы книги (Тихонова (Ред.), 2018) делают обоснованное предположение, что подобные шкалы создают основу для принятия новаций по совершенствованию режимов налогообложения. Работа свидетельствует о неоднозначности оценок уровня неравенства и интерпретации различными исследователями, невозможности получения единственного абсолютно верного результата.

${ }^{10}$ URL: https://www.forbes.ru/newsroom/milliardery
В последнее время в число источников информации о монетарном неравенстве стали включаться наряду с другими данные налоговой статистики. Впервые налоговые данные в исчислении уровня неравенства использовали С.М. Гуриев и А.А. Рачинский ${ }^{11}$, затем К.О. Бутаева (2017). Вслед появилась вызвавшая широчайшую полемику публикация (Novokmet, Piketty, Zucman, 2018). Во всех работах, использующих налоговую статистику, коэффициент Джинни в России близок или более чем 0,5 .

Борьба с бедностью как проявлением монетарного неравенства является одной из приоритетных целей российского государства. В Указе Президента РФ от 21.07.2020 г. № 474 «О национальных целях развития Российской Федерации на период до 2030 года» говорится о снижении бедности в два раза по сравнению с 2017 г. Полагаем, что для достижения подобного результата крайне востребованным является совершенствование подоходного налогообложения в части выведения из-под НДФЛ доходов, не превышающих прожиточный минимум.

Одновременно уменьшение неравенства по доходам возможно путем введения прогрессивной шкалы по НДФЛ для богатых и супербогатых налогоплательщиков (шпиля по неравенству). Такое воздействие на «хвост» и «шпиль» групп населения по уровню доходов в определенной степени нивелирует уровень неравенства. Синхронное введение соответствующих налоговых новаций позволит не только не потерять налоговые доходы бюджетной системы, но и пополнить государственную казну поступлениями денежных средств от олигархической верхушки.

Для конкретизации высказанных предложений относительно направлений реформирования НДФЛ в России рассмотрим специфику подоходного налогообложения в странах ОЭСР.

\section{Подоходное налогообложение в странах ОЭСР}

Согласно данным eLibrary, словосочетание «подоходный налог» содержится в

11 Гуриев С., Рачинский А. 2006. Неравенство: Рио-де-Москва. Ведомости. № 85. URL: https://pandia.ru/ text/80/603/81238.php 
названии, аннотации, ключевых словах около 600 книг и журналов. В 35 из них в той или иной степени освещаются проблемы неравенства и делаются различные выводы о целесообразности введения прогрессивной шкалы НДФЛ в России. Так, Е.В. Балацкий и Н.А. Екимова (Balatsky, Ekimova, 2019), С.А. Белозеров и Е.В. Cоколовская (Belozyorov, Sokolovska, 2018) выступают против нее, а Т.В. Муравлева и Д.Д. Орловская (2019), Е.А. Тарапатина (2019), Д.Е. Лапов и И.А. Майбуров (2020) - за ее введение.

Поддерживая обоснования неэффективности плоской шкалы НДФЛ и значимости прогрессии, содержащиеся в статье Д.Е. Лапова и И.А. Майбурова (2020), считаем целесообразным дополнить их аргументы анализом практики налогообложения доходов физических лиц в странах ОЭСР.

Согласно сайту ОЭСР, в Тах Database доступна информация по 35 странам-членам ОЭСР за последние 20 лет, содержащая в табличной форме данные о ставках и шкалах подоходного налога физических лиц, установленных на федеральном уровне ${ }^{12}$.

Рассмотрим основные положения, регулирующие порядок исчисления PIT в странах ОЭСР в 2019 г.

Личный вычет (необлагаемая сумма), т. е. льгота в фиксированной сумме, установлена в 14 странах. При переводе национальных валют в рубли получаем, что на первом месте по уровню необлагаемой суммы стоит Норвегия - 1107481 руб., далее идут США - 755250 руб. (где кроме этого есть также налоговый кредит по НДФЛ), затем Бельгия - 614686 руб. Самое низкое значение зафиксировано у Мексики 14110 руб. Среднее значение необлагаемой суммы составляет 319538 руб. в год, или 26628 руб. в месяц.

В 5 государствах кроме необлагаемых сумм законодательством предусмотрен налоговый кредит по РIT: США, Польше, Мексике, Исландии, Норвегии.

Налоговый кредит выдается по индивидуальному подоходному налогу в 12 государствах. При переводе сумм из национальных валют в рубли на первом месте оказывается

${ }^{12}$ URL: https://stats.oecd.org/index.aspx?DataSetCode= TABLE_I1
Ирландия - 189443 руб., далее Нидерланды - 171849 руб., Израиль - 136968 руб. На последнем месте находится Исландия 11786 руб. В среднем размер налогового кредита составляет 80168 руб.

C учетом размера налогового кредита общая сумма льготы в месяц составляет в среднем 33309 руб. (399 707 руб. : 12 месяцев), т. е. сумму практически трех российских прожиточных минимумов.

Целесообразно для успешного выполнения планов по снижению уровня бедности в два раза к 2030 г. внести изменения в НК РФ в части необложения НДФЛ доходов на сумму менее двойного размера прожиточного минимума, записав это как стандартный налоговый вычет.

Анализ уровня ставок индивидуального подоходного налога в странах ОЭСР, устанавливаемых на федеральном уровне, показал, что из 35 государств только 3 не имеют прогрессивной шкалы: Эстония, Чешская Республика и Венгрия. Максимальное количество шедул в Люксембурге (19), Мексике и Швейцарии (11). В 7 странах - 7 шедул, $11-5$ шедул, $4-4$ шедулы, 2 - 3 шедулы, 5 - 2 шедулы.

В 2019 г. самые высокие ставки РIT на федеральном уровне были в Австрии (55\%), Нидерландах (51,75\%), Бельгии, Израиле, Словении (50\%). Самая низкая ставка - в Швейцарии (11,5\%), затем следуют Венгрия, Чешская Республика (15\%).

Кроме ставок индивидуального подоходного налога на федеральном уровне, существует дополнительное налогообложение на соответствующих региональном, штатном, кантональном и провинциальном уровнях.

В 9 странах названное налогообложение осуществляется на непрогрессивной основе ${ }^{13}$. Дания, Финляндия, Исландия, Италия, Япония, Корея, Норвегия, Швеция, США.

Самая высокая репрезентативная ставка установлена в Швеции - 32,19\% (в диапазоне от 29,18 до 35,15\%). Далее идут: Дания - 24,93\% (от 22,50 до 27,80\%), Финляндия - 19,88\% (от 17,00 до 22,50\%), Исландия 14,44\% (от 12,44 до 14,52), Норвегия $-14,5 \%$ (от 0 до $14,5 \%$ ), Япония и

${ }^{13}$ Sub-central personal income tax rates-non-progressive systems URL: https://stats.oecd.org/index.aspx? DataSetCode= TABLE_I2 
Корея - 10\%, Италия - 1,73-3,33\%, в США ставка равняется 4,25\% на уровне штатов плюс $2,4 \%$ на местном уровне.

В 4 странах налогообложение на субфедеральном уровне происходит с использованием прогрессивной шкалы ${ }^{14}$.

В Бельгии используется ставка $6,4 \%$, к которой прибавляется от 25 до 50\%.

В Канаде ставки колеблются от 5,1 до 13,2\%, в Испании - от 9 до 13,2\%.

В Швейцарии есть единовременный налог по правилам региона, к нему плюсуется налог по ставке 19\% и далее по прогрессии от 2 до $13 \%$.

В странах ОЭСР в 2019 г. сумма подоходного налога, взносов работодателей на социальное обеспечение и работников на обязательное медицинское страхование составляла в среднем $36 \%$ от затрат на рабочую силу, колеблясь от $52,2 \%$ в Бельгии до $7 \%$ в Чили. Согласно расчетам аналитических служб ОЭСР, в 2019 г. средний показатель по странам составлял 43\%, что ниже уровня 2000 г. на 2,6 п. п. Снижение ставок произошло в ряде государств. Больше всего они сократились в Венгрии: с 40 до 15\%. При этом с 2007 г. в 23 странах зафиксировано повышение ставок PIT $^{15}$.

Приведенная в этом разделе информация по индивидуальному подоходному налогообложению в странах ОЭСР свидетельствует о наличии прогрессивной шкалы PIT в подавляющем большинстве государств и об использовании ими необлагаемых данным налогом сумм и системы налоговых кредитов. Показатели же уровня неравенства в этих юрисдикциях, как правило, ниже, чем в России.

Изучение научных публикаций и расчетов различных международных организаций свидетельствует, что уровень монетарного неравенства в части доходов в России существенно выше, чем в большинстве стран ОЭСР. Исследователи неравенства справедливо полагают, что одним из знаTABLE I3

${ }^{14}$ URL: https://stats.oecd.org/index.aspx?DataSetCode=

${ }^{15}$ URL: https://www.oecd.org/tax/tax-policy/taxdatabase-update-note.pdf чимых факторов уменьшения уровня неравенства является использование прогрессивной шкалы PIT и необлагаемых подоходным налогом сумм. Анализ налоговых систем стран ОЭСР показал, что при низком уровне монетарного доходного неравенства в законодательстве данных государств действует прогрессивное налогообложение и установлены необлагаемые PIT суммы.

Передовой опыт стран ОЭСР свидетельствует, что для снижения уровня неравенства доходов населения целесообразно для богатых и супербогатых налогоплательщиков вводить прогрессивную шкалу НДФЛ, состоящую из 4-6 уровней и доходящую до размера налоговой ставки не менее $40 \%$. Выше названного уровня устанавливать ставку вряд ли целесообразно, так как это может привести к оттоку денежных средств из России в другие юрисдикции. Надо надеяться, что введение с 1 января 2021 г. в России налогообложения по ставке 15\% доходов, превышающих 5 млн руб., является полумерой временного характера и в дальнейшем произойдет осознание необходимости обложения доходов олигархического «шпиля» российского общества по более высоким ставкам. Подобная новация позволит не только нивелировать, снижать «шпиль» по неравенству, но и будет способствовать увеличению доходов бюджетной системы. Для решения проблемы по сглаживанию неравенства в части подтягивания «хвоста» к середине следует одновременно установить необлагаемую НДФЛ сумму в размере не менее двух прожиточных минимумов. Эти новации в совокупности будут способствовать обеспечению устойчивости среднедоходных слоев населения.

Точные расчеты пороговых значений прогрессивной шкалы возможны на основе полномасштабного использования данных ФНС РФ, а не только тех, которые имеются в настоящее время в открытом доступе.

Комплексное изучение проблем измерения уровня монетарного неравенства доходов населения и опыта налогообложения индивидуальных доходов граждан в различных странах открывает широкие перспек- 
тивы для разработки направлений развития теории и практики в названных отраслях знаний и грамотного научно обоснованного реформирования подоходного налогообложения в России в целях достижения задач социально-экономического развития страны в среднесрочной перспективе.

\section{СПИСОК ЛИТЕРАТУРЫ (REFERENCES)}

Авраамова Е.М., Малева Т.М. 2014. О причинах воспроизводства социально-экономического неравенства: что показывает ресурсный подход? Вопросы экономики. № 7. С. 144-160. [Avraamova E.M., Maleva T.M. 2014. On the causes of socioeconomic inequality reproduction: What does resources approach show? Voprosy ekonomiki. No 7. PP. 144-160. (In Russ.)]

Бутаева К.О. 2017. Неравенство доходов как объект экономических исследований в контексте анализа уровня жизни и общественного благосостояния. Вестник Тюменского государственного университета. Социально-экономические и правовые исследования. Т. 3. № 3. С. 71-86. [Butaeva K.O. 2017. Income inequality as an object of economic research in the context of analyzing the standard of living and public welfare. Vestnik Tyumenskogo gosudarstvennogo universiteta. Sotsial'no-ekonomicheskie i pravovye issledovaniya. Vol. 3. No 3. PP. 71-86. (In Russ.)]

Викторова Н.Г., Аитова Л.К. 2016. Подоходный налог в странах БРИКС: аналитический аспект. Актуальные проблемы науки и практики. № 1 (002). C. 22-26. [Viktorova N.G., Aitova L.K. 2016. Income tax in the BRICS countries: analytical aspect Aktual'nye problemy nauki $i$ praktiki. No 1 (002). PP. 22-26. (In Russ.)]

Вылкова Е.С. 2017. Методические подходы к оценке уровня справедливости налогового законодательства. Экономика. Налоги. Право. Т. 10. № 4. C. 6-13. [Vylkova E.S. 2017. Methodical approaches to assessing the fairnessof tax legislation. Ekonomika. Nalogi. Pravo. Vol. 10. No 4. PP. 6-13. (In Russ.)]

Вылкова Е.С., Красавин В.И. 2011. Формирование налоговых льгот в субъектах Российской Федерации (на примере СЗФО). Санкт-Петербург: Центр подготовки персонала Федеральной налоговой службы. 277 с. [Vylkova E.S., Krasavin V.I. 2011. Formation of tax benefits in the constituent entities of the Russian Federation (by the example of the NWFD). St. Petersburg: Tsentr podgotovki personala Federal'noy nalogovoy sluzhby. 277 p. (In Russ.)]

Вылкова Е.С., Тарасевич А.Л. 2010. Концептуальные основы реформирования налога на доходы физических лии в России. Санкт-Петер- бург: Издательство СПбГЭУ. 211 с. [Vylkova E.S., Tarasevich A.L. 2010. Conceptual framework for reforming the tax on personal income in Russia. St. Petersburg: Izdatel'stvo SPbGEU. 211 p. (In Russ.)]

Вылкова Е.С., Тарасевич А.Л. 2017. Совершенствование налогообложения доходов и имущества физических лиц в России на основе справедливо-действенного подхода. Проблемы современной экономики. № 3. С. 38-42. [Vylkova E.S., Tarasevich A.L. 2017. Improving taxation of profits and property of Russia's physical persons on the basis of justice-and-efficacy approach. Problemy sovremennoy ekonomiki. No 3. PP. 38-42. (In Russ.)]

Вылкова Е.С., Тарасевич А.Л. 2018. Совершенствование налогообложения труда в странах ОЭСР и Российской Федерации. Экономика. Налоги. Право. № 3. С. 114-121. [Vylkova E.S., Tarasevich A.L. 2018. Improving labor taxation in OECD countries and the Russian Federation. Ekonomika. Nalogi. Pravo. No 3. PP. 114-121. (In Russ.)]

Вылкова Е.С., Шматко А.Д. 2020. Налогоплательщики налога на доходы физических лиц как значимые участники инициативного бюджетирования. Белорусский экономический журнал. № 2. C. 143-152. [Vylkova E.S. Shmatko A.D. 2020. Income tax payers as significant participants of proactive budgeting. Belorusskiy ekonomicheskiy zhurnal. No 2. PP. 143-152. (In Russ.)]

Григорьев Л.М., Павлюшина В.А. 2017. Социальное неравенство как проблема экономической стратегии России. Мир новой экономики. № 3. С. 5871. [Grigoryev L.M., Pavlyushina V.A. 2017. Social inequality as a problem of Russia's economic strategy Mir novoy ekonomiki. No 3. PP. 58-71. (In Russ.)]

Капелюшников Р.И. 2017. Неравенство: как не примитизировать проблему. Вопросы экономикu. № 4. C. 117-139. [Kapeliushnikov R.I. 2017. Inequality: How not to primitize the problem. Voprosy ekonomiki. No 4. PP. 117-139. (In Russ.)]

Капелюшников Р.И. 2019. Экономическое неравенство - вселенское зло? Вопросы экономикu. № 4. C. 91-106. [Kapeliushnikov R.I. 2019. Is economic inequality a universal evil? Voprosy ekonomiki. No 4. PP. 91-106. (In Russ.)]

Капелюшников Р.И. 2020. Команда Пикетти о неравенстве в России: коллекция статистических артефактов. Вопросы экономики. № 4. С. 67-106. [Kapeliushnikov R.I. 2020. PIketty's team on inequality in Russia: A collection of statistical artifacts. Voprosy ekonomiki. No 4. PP. 67-106. (In Russ.)]

Киреева Е.Ф. 2012. Налоговая политика стран - членов Европейского союза и государств членов Таможенного союза: проблемы конкурентоспособности и гармонизации. Белорусский экономический журнал. № 4. C. 57-73. [Kireyeva E.F. 2012. Tax policies of the European Union Countries 
and the Customs Union Member States: Problems of competitiveness and harmonization. Belorusskiy ekonomicheskiy zhumal. No 4. PP. 57-73. (In Russ.)]

Конягина М.Н. 2019. Зарубежный опыт применения цифрового инструментария прогнозирования налоговых поступлений в бюджет. Научные труды Северо-Западного института управления РАНХиГС. Т. 10. № 3. С. 127-136. [Koniagina M.N. 2019. Foreign experience of the application of digital instruments for forecasting tax income to the budget. Nauchnye trudy SeveroZapadnogo instituta upravleniya RANKhiGS. Vol. 10. No 3. PP. 127-136. (In Russ.)]

Лаврентьева Е.А. 2016. Налогообложение доходов работников водного транспорта. СанктПетербург: ГУМРФ им. адмирала С.О. Макарова. 180 c. [Lavrentyeva E.A. 2016. Taxation of income of water transport workers. Sankt-Peterburg: GUMRF im. admirala S.O. Makarova. 180 p. (In Russ.)]

Лапов Д.Е., Майбуров И.А. 2020. Возможности учета реальной налоговой нагрузки при моделировании шкалы подоходного налогообложения. Journal of Applied Economic Research. T. 19. № 2. C. 129-148. [Lapov D.E., Mayburov I.A. 2020. Possibilities of taking into account the real tax burden when modeling the scale of income taxation. Journal of Applied Economic Research. Vol. 19. No 2. PP. 129-148. (In Russ.)]

Мареева С.В. 2016. Монетарные и немонитарные неравенства в жизни россиян. Социологические исследования. № 10. С. 65-74. [Mareeva S.V. 2016. Monetary and non-monetary inequalities in Russians' lives. Sotsiologicheskie issledovaniya. No 10. PP. 65-74. (In Russ.)]

Мареева С.В. 2018. Социальные неравенства и социальная структура современной России в восприятии населения. Вестник института социологии. Т. 9. № 3. С. 101-120. [Mareeva S.V. 2018. Social inequalities and the social structure of modern Russia as perceived by the population. Vestnik instituta sotsiologii. Vol. 9. No 3. PP. 101120. (In Russ.)]

Мареева C.B. 2020. Монетарное неравенство в России в социологическом измерении. Вестник института социологии. Т. 11. № 3. С. 7898. [Mareeva S.V. 2020. Monetary inequality in Russia in the sociological dimension. Vestnik instituta sotsiologii. Vol. 11. No 3. PP. 78-98. (In Russ.)]

Мареева С.В., Слободенюк Е.Д. 2018. Неравенство в России в международном контексте: доходы, богатство, возможности. Вестник общественного мнения. Данные. Анализ. Дискуссии. № 1-2 (126). C. 30-46. [Mareeva S.V., Slobodenyuk E.D. 2018. Inequality in Russia in the International Context: Income, Wealth, Opportunities. Vestnik obshchestvennogo mneniya. Dannye. Analiz. Diskussii. № 1-2 (126). PP. 30-46. (In Russ.)]
Муравлева Т.В., Орловская Д.Д. 2019. Опасные рифы и триумфы введения прогрессивной шкалы по НДФЛ в России. Экономическая безопасность и качество. № 3. С. 50-54. [Muravleva T.V., Orlovskaya D.D. 2019. Dangerous pitfalls and triumphs of the introduction of a progressive scale of personal income tax in Russia. Ekonomicheskaya bezopasnost' $i$ kachestvo. No 3. PP. 50-54. (In Russ.)]

Овчарова Л.Н., Попова Д.О., Рудберг А.М. 2016. Декомпозиция факторов неравенства доходов в современной России. Журнал Новой экономической ассощиации. № 3. С. 170-186. [Ovcharova L.N., Popova D.O., Rudberg A.M. 2016. Decomposition of income inequality in contemporary Russia. Zhumal Novoy ekonomicheskoy assotsiatsii. No 3. PP. 170-186. (In Russ.)]

Орлова Е.Н., Быков С.С. 2012. Роль налоговых расходов местных бюджетов в формировании налогового потенциала. Проблеми Економіки. № 3. C. 36-46. [Orlova E.N., Bykov S.S. 2012. Local budgets tax expenditures's role in formation of tax capacity. Problemy Ekonomiki. No 3. PP. 3646. (In Russ.)]

Покровская Н.В. 2017. Зачисление налога на доходы физических лиц в местные бюджеты в Российской Федерации. Экономика. Налоги. Право. № 3. С. 146-151. [Pokrovskaya N.V. 2017. The payment of the personal income tax to local budgets in the Russian Federation. Ekonomika. Nalogi. Pravo. No 3. PP. 146-151. (In Russ.)]

Салмина А.А. 2019. Индикатор неравенства Аткинсона как альтернатива Джини: оценки для России. Социальная политика и социология. Т. 18. № 3. C. 83-92. [Salmina A.A. 2019. Atkinson's inequality measure as an alternative to gini: Estimates for Russia. Sotsial'naya politika i sotsiologiya. Vol. 18. No 3. PP. 83-92. (In Russ.)]

Тарапатина Е.А. 2019. К вопросу о введении прогрессивной шкалы НДФЛ в России. Тендениии развития науки и образования. № 47-3. C. 75-78. [Tarapatina E.A. 2019. On the issue of introducing a progressive scale of personal income tax in Russia. Tendentsii razvitiya nauki i obrazovaniya. No 47-3. PP. 75-78. (In Russ.)]

Тихонова Н.Е. (Ред.). 2018. Модель доходной стратификации российского общества: динамика, факторы, межстрановые сравнения. Москва, СПб.: Нестор-История. 368 с. [Tikhonova N.E. (Ed.). 2018. Model of income stratification of Russian society: Dynamics, factors, cross-country comparisons. Moscow, SPb.: Nestor-Istoriya. 368 p. (In Russ.)]

Atkinson A.B. 2015. Inequality: What can be done? Harvard University Press. 400 p.

Balatsky E.V., Ekimova N.A. 2019. Evaluating scenarios of personal income tax reform in Russia. Journal of Tax Reform. Vol. 5. No 1. PP. 6-22. 
Belozyorov S. A., Sokolovska O.V. 2018. Personal income taxation and income inequality in Asia-Pacific: a cross-country analysis. Journal of Tax Reform. Vol. 4. No 3. PP. 236-249.

Cebula R.J. 2019. An Empirical Analysis of the Effects of Budget Deficits (Total and Primary) and Personal Income Tax Rates on the Ex Post Real Interest Rate Yield on Long-Term U.S. Treasury Bonds. Review of Economic Analysis. Vol. 11. Iss. 2. PP. 203-218.

Grusky D. 2011. The Stories About Inequality That We Love to Tell. The Inequality Reader. Contemporary and Foundational Readings in Race, Class, and Gender. Westview Press. PP. 1-13.

Kim H.-J. 2018. Some models for progressive taxation. Communications of the Korean Mathematical Society. Vol. 33. Iss. 3. PP. 823-831.
Milanovic B. 2016. Global inequality: A new approach for the age of globalization. Cambrige, Massachusetts: Harvard University Press. 320 p.

Novokmet F., Piketty T., Zucman G. 2018. From Soviets to Oligarchs: Inequality and Property in Russia 1905-2016. The Journal of economic Inequality. Vol. 16. PP. 189-223.

Paes N.L., Bugarin M.N.S. 2006. Reforma tributária: Impactos distributivos, sobre o bem-estar e a progressividade. Revista Brasileira de Economia Vol. 60. Iss. 1. PP. 33-56.

Piketty T. 2014. Capital in the Twenty-First Century. Harvard University Press. 685 p.

Stiglitz J. 2012. The price of inequality: how today's divided society endangers our future. New York, London: W.W. Norton \& Company. 560 p.

\section{PERSONAL INCOME TAX IMPROVEMENT TO REDUCE THE LEVEL OF MONETARY INEQUALITY}

\section{Elena Vylkova ${ }^{1}$}

Author affiliation: ${ }^{1}$ North-West Institute of Management of the Russian Academy of National Economy and Public Administration (St. Petersburg, Russia).

Corresponding author: Elena Vylkova (vylkova-es@ranepa.ru).

ABSTRACT. The article analyzes different methods of measuring for the level of income monetary inequality. It deals with the problem of relevant indicators obtainment and their calculation validity, as well as with their features both for the state and regions. Based on the data of the World Bank, the Federal State Statistics Service, and some other organizations, the results of statistical calculations for the level of income monetary inequality are given. Forms and stratification variants of income monetary inequality in different countries and in Russia are considered. Even though the results obtained are disputable due to the measurement deviations, it is possible to conclude that the level of income inequality among the mainstream society in Russia is higher in comparison with the European states, but lower than in BRICS member countries. Analysis of personal income taxation system in OECD member countries is carried out. Suggestions on reforming personal income tax assessment in Russia.

KEYWORDS: monetary inequality, personal income, tax, progressive taxation, cost of living.

JEL-code: D63, H21, H24.

DOI: $10.46782 / 1818-4510-2021-2-46-54$

Received 12.04.2021 